\title{
Subarachnoid Hemorrhage Following Masturbation: The Significance of Eliciting Detail Clinical History
}

Gentle Sunder Shrestha ${ }^{1,2 *}$, Kenison Shrestha ${ }^{2}$, Gopal Sedain ${ }^{3}$, Mohan R Sharma ${ }^{3}$

${ }^{1}$ Department of Anaesthesiology, Institute Of Medicine, Tribhuvan UniversityTeaching Hospital, Kathmandu, Nepal

${ }^{2}$ Department of Critical Care, Alka Hospital Pvt. Ltd, Jawalakhel, Lalitpur, Nepal

${ }^{3}$ Neurosurgery Unit, Tribhuvan Univerity Teaching Hospital, Maharajgunj, Kathmandu, Nepal

\section{Letter to the Editor}

A 36 years old patient presented with severe headache of 4 hours duration, not relieved with non-steroidal anti-inflammatory agents. $\mathrm{He}$ did not have history of loss of consciousness or trauma. His Glasgow Coma Scale score was 15, oriented to time, place and person and with intact cranial nerves. Neck rigidity and fever were absent. His blood pressure was 140/80 $\mathrm{mm} \mathrm{Hg}$. Laboratory investigation reports including the platelet count and prothrombin time were normal. Detail history revealed that the headache had started abruptly just after ejaculation during masturbation while bathing. CT scan of the head revealed subarachnoid hemorrhage (Figure 1). Patient was transferred to high volume centre. CT cerebral angiography revealed saccular aneurysms arising from bilateral ophthalmic segments of internal carotid arteries (Figure 2). Both the aneurysms were secured by clipping after around 48

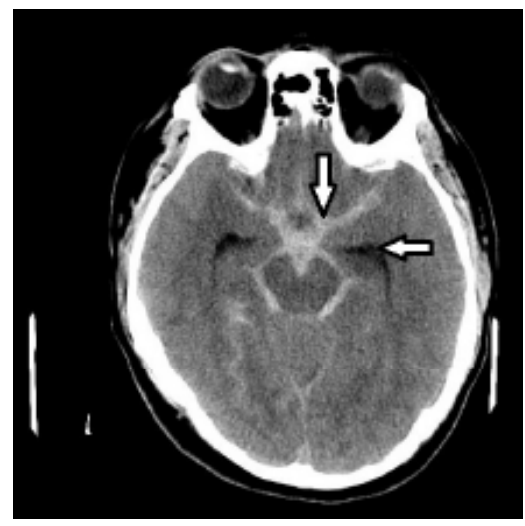

Figure 1: CT Head showing dense subarachnoid blood in basal cistern (vertical arrow) and prominent temporal horn of lateral ventricle (horizontal arrow).

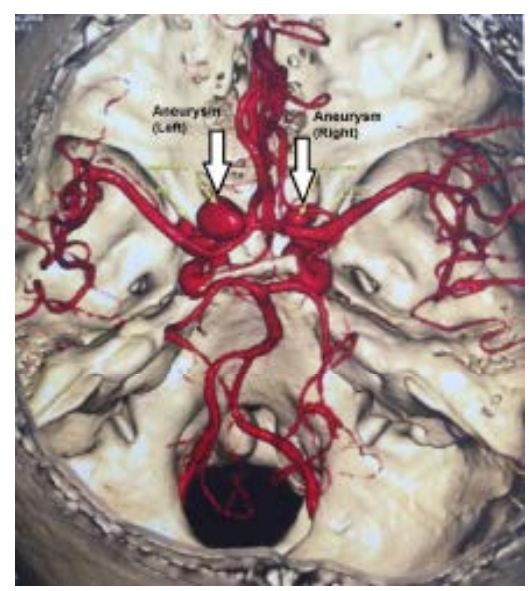

Figure 2: CT Cerebral Angiography with 3D reconstruction showing $16.1 \times 11.4 \mathrm{~mm}$ saccular aneurysm in left and $7.5 \times 5.9 \mathrm{~mm}$ saccular aneurysm in right ophthalmic segment of internal carotid arteries (indicated by vertical arrows) hours of ictus and the patient had uneventful recovery with no residual neurological deficits. Patient had no residual neurological deficits when he attended the hospital clinic 3 months after the ictus.

Rupture of an intracranial aneurysm accounts for about 80 percent of cases of non-traumatic subarachnoid hemorrhage (SAH) and has a high rate of death and complications [1]. Vast majority of patients experience abrupt onset of severe headache, which may be associated with loss of consciousness, vomiting, photophobia, neck pain or stiffness. In the absence of classic signs and symptoms, SAH may be misdiagnosed in upto $12-25 \%$ of patients [2]. Misdiagnosed patients tend to be less ill and have a normal neurological examination. In such cases, neurological complications occur late in as many as 50 percent of patients and these patients have an associated higher risk of death and disability [3].

Cerebral aneurysm rupture has been associated with sexual intercourse and other form of physicial exercises. Multiple case series reported coitus as the immediate preceeding activity in $3.8-14.5 \%$ of patients suffering from aneurysmal SAH. Acute elevation of blood pressure and acute reduction in intracranial pressure are the two key factors promoting aneurysmal rupture. It together leads to elevation of transmural pressure gradient and subsequent increased aneurysmal wall tension, culminating into increased risk of rupture of aneurysm [4]. Similar mechanism hold true during masturbation. There are reports of sudden death following sexual anal self-stimulation due to massive subarachnoid hemorrhage from a ruptured berry aneurysm [5].

To conclude, failure to diagnose subarachnoid hemorrhage following spontaneous rupture of aneurysm is associated with poor outcome. It is not uncommon following coitus or sexual stimulation. Clinical vigilance and eliciting detail clinical history can help to minimize misdiagnosis.

\section{References}

1. van Gijn J, Rinkel GJ (2001) Subarachnoid hemorrhage: diagnosis, causes and management. Brain 124: 249-278.

2. Edlow JA, Caplan LR (2000) Avoiding pitfalls in the diagnosis of subarachnoid hemorrhage. N Engl J Med 342: 29-36.

*Corresponding author: Gentle Sunder Shrestha, Department of Anaesthesiology Tribhuvan University Teaching Hospital, Institute of Medicine, Maharajgunj, Kathmandu, Nepal, Tel: +977-9841248584; E-mail: gentlesunder@hotmail.com

Received July 03, 2015; Accepted August 02, 2015; Published August 10, 2015

Citation: Shrestha GS, Shrestha K, Sedain G, Sharma MR (2015) Subarachnoid Hemorrhage Following Masturbation: The Significance of Eliciting Detail Clinical History. Brain Disord Ther 4:177. doi:10.4172/2168-975X.1000177

Copyright: (c) 2015 Shrestha GS, et al. This is an open-access article distributed under the terms of the Creative Commons Attribution License, which permits unrestricted use, distribution, and reproduction in any medium, provided the original author and source are credited. 
Citation: Shrestha GS, Shrestha K, Sedain G, Sharma MR (2015) Subarachnoid Hemorrhage Following Masturbation: The Significance of Eliciting Detail Clinical History. Brain Disord Ther 4:177. doi:10.4172/2168-975X.1000177

Page 2 of 2

3. Suarez JI, Tarr RW, Selman WR (2006) Aneurysmal subarachnoid hemorrhage. N Engl J Med 354: 387-396.

4. Reynolds MR, Willie JT, Zipfel GJ, Dacey RG (2011) Sexual intercourse and cerebral aneurysmal rupture: potential mechanisms and precipitants. $J$ Neurosurg 114: 969-977

5. Nikolic S, Zivkovic V (2012) Fatal subarachnoid hemorrhage during sexual ana self-stimulation in a female: a case report. Am J Forensic Med Pathol 33: 152-155. 